\title{
Assessment of Patient Safety Culture among Nurses at a Tertiary Level Hospital in Kathmandu
}

\section{*Sabitra Poudel ${ }^{1}$, Menuka Aryal' ${ }^{2}$, Narayani Paudel ${ }^{3}$}

${ }^{1}$ Lecturer, Department of Nursing, Kathmandu Medical College Public Limited, Kathmandu University, Nepal

${ }^{2}$ Department of Nursing, Kathmandu Medical College Public Limited, Kathmandu University, Nepal ${ }^{3}$ Associate Professor Department of Nursing, Kathmandu Medical College Public Limited, Kathmandu University, Nepal

\section{*Corresponding Author:}

Sabitra Poudel, Lecturer

E-mail: sabitrapoude1010@gmail.com

\begin{abstract}
Introduction: Patient safety is a fundamental and critical dimension of quality health care. Globally it is becoming a major challenge in achieving universal health coverage. The challenge is even more serious in Low and Middle Income Countries like Nepal because safety related harm is more in these countries rather than in developed countries. This study aims to assess the patient safety culture among nurses.
\end{abstract}

Methods: A descriptive cross-sectional study was conducted at Kathmandu Medical College Public Limited to assess the Patient Safety Culture within the organization among nurses. The data was collected using Agency for Health Care Research and Quality (AHRQ) Hospital survey on patient safety culture questionnaire. Mean score was calculated in different dimensions and Mann-Whitney U test was used to assess the association between safety dimension and demographic variables.

Result: Among 12 areas of patient safety, teamwork within units and organizational learning had the highest mean score whereas the lowest reported score was in staffing followed by supervisor's expectation and action promoting patient safety. While rating the extent of patient safety, $84 \%$ of respondents reported it as average in the organization. Study showed significant association of management support, organizational learning and frequency of event reported with age of respondents and overall perception of patient safety and hands-off/transition with working area.

Conclusion: Since the patient safety culture is average within organization, attention needs to be paid to make it adequate in all areas of safety.

Keywords: Hospital, Nurses, Patient safety culture, Safety.

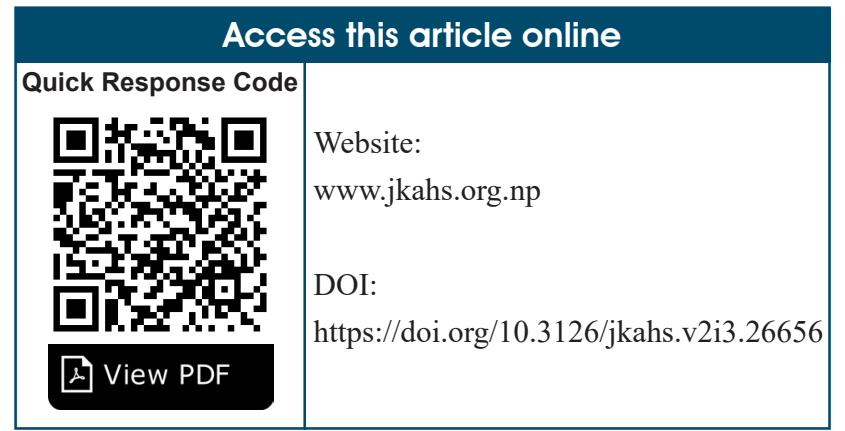

www.jkahs.org.np

\section{Article Info.}

\section{How to cite this article?}

Poudel S, Aryal M, Paudel N. Assessment of Patient Safety Culture among Nurses at a Tertiary Level Hospital in Kathmandu. Journal of Karnali Academy of Health Sciences. 2019;2(3): 203-208.

Received: 18 Sep., Accepted: 20 Nov., Published: 11 Dec. 2019

Conflict of Interest: None, Source of Support: None 


\section{INTRODUCTION}

Patient safety is the absence of preventable harm and reduction of risk of unnecessary harm associated with health care services to an acceptable minimum that means collective notions of given current knowledge, resources available, and the context in which care was delivered weighed against the risk of non-treatment or other treatment. ${ }^{1}$ The problem of adverse events like health care associated infection, fall injuries, medication error etc. in health care setting is not new. Studies as early as the 1950s and 1960s reported on adverse events, but it remained largely neglected. ${ }^{2}$ There is now growing recognition that patient safety and quality is a critical dimension of universal health coverage. The health care system is in starting phase to recognize the underlying barriers to improvement in safety such as lack of transparency, sharing of data, honesty among professionals and organizations, and the importance of a truly supportive safety culture. ${ }^{3}$ The culture means "the way people do things around there" so in health care setting safety culture incorporates understanding the shared attitudes, beliefs and values of healthcare workers and the degree to which these influence safety behaviors for patient within the organizations. ${ }^{4}$

It is estimated that, in the hospitals of developed countries, one in ten patients is harmed because of unsafe care. Among every 100 hospitalized patient seven in developed and ten in developing country acquire health care associated infections. The risk is twenty times higher in some developing countries. ${ }^{5}$ The estimates shows that as many as 98,000 people die in any given year from medical errors occurring in hospitals, which is more than death from motor vehicle accidents, breast cancer or HIV AIDS, the three major causes receiving far more public attention. ${ }^{6}$ Australian data reveals that $16.6 \%$ of hospital admissions were associated with an "adverse event" of which more than half i.e. $51 \%$ were considered preventable adverse events. Among those admissions in $77.1 \%$ the disability had resolved within 12 months, in $13.7 \%$ the disability was permanent and in $4.9 \%$ the patient died. ${ }^{7}$ Poor quality health care around the globe causes ongoing damage to human health. This is even more in low-and middle-income countries (LMICs). In LMICs each year between 5.7 and 8.4 million deaths occur from poor quality of health care which means that quality health care defects lead to $10-15$ percent of total deaths in these countries. ${ }^{8}$

As literature suggests safety related harm is more in low and middle income countries (LMICs) rather than in developed countries, Nepal being a LMICs it is important to focus on patient safety to reduce health care related harm to clients. A study conducted in Turkey showed that $48.8 \%$ of potential threat to patient safety is fall. They reported the patient safety in their institution as acceptable (43\%). Out of the 12 dimensions of Hospital Survey on Patient Safety Culture, the percentage of positive responses was the highest for "teamwork within units" and lowest for the "non-punitive response to error". ${ }^{9}$ In a study from Nepal 64\% nurses reported patient safety culture within organization as adequate. Among different dimensions of safety it showed teamwork, organizational learning and feedback as strong areas and management support, non-punitive response and staffing as weak areas 10. Assessing health care professionals' perception, in patient safety culture plays a crucial role towards initiation of safety culture within organization. Moreover nurses always being in the front line health care provider, nurses reported patient safety culture is even more important. Hence, this study is deemed necessary to assess the nurses' perception of patient safety culture in Kathmandu Medical College Sinamangal, Kathmandu.

\section{MATERIALS AND METHODS}

A descriptive - cross sectional study design was used to assess patient safety culture among nurses at Kathmandu Medical College Public Limited. There were total 294 nurses working in different units of hospital. The calculated sample size was 93 using formula for finite population with perceived adequate patient safety proportion of $65 \%{ }^{10}$ Then quota sampling technique was used to get proportionate representation of all units. Data was collected by using Agency for Health Care Research and Quality (AHRQ) Hospital Survey on Patient Safety Culture 
questionnaire, which comprises 12 patient safety areas with 42 items in it. For each item participants responded as strongly agree to strongly disagree. ${ }^{11}$ Mean score was calculated in each dimension. Ethical approval was obtained from Institutional Review Committee of Kathmandu Medical College. Written

\section{RESULT}

Table 1: Socio-Demographic Characteristics of Respondents ( $n=93$ )

\begin{tabular}{lcc}
\hline Characteristics & Frequency & Percentage (\%) \\
\hline Age (in years) & & 50.5 \\
$20-25$ & 47 & 44.1 \\
$25-30$ & 41 & 5.4 \\
$>30$ & 5 & \\
Mean \pm S.D. 25.63 \pm 3.1 & \\
Marital status & & 53.8 \\
Married & 50 & 46.2 \\
Unmarried & 43 & \\
Professional & & \\
qualification & & 46.2 \\
PCL Nursing & 43 & 53.8 \\
Bachelor in & 50 & \\
Nursing & & \\
Experience & & 41 \\
$\leq 5$ years & 66 & \\
5-10 years & 23 & \\
$>10 y e a r s$ & 4 & \\
Mean \pm SD: $4.44 \pm 1.7$ & & \\
\hline
\end{tabular}

Table one shows that the mean $\pm \mathrm{SD}$ age of respondents was $25.63 \pm 3.1$ where half of the respondents were from age group 20-25 years. More than fifty percent were married and had graduate level of professional education. Seventy-one percentages of respondents had working experience of less than five years. informed consent was obtained from respondents prior to data collection and self-administered questionnaire was used for data collection procedure. Collected data was entered in Microsoft Excel and analyzed by using Statistical Package for Social Sciences (SPSS) version 16.

Table 2: Mean score and rank in different areas of patient safety culture $(n=93)$

\begin{tabular}{lcc}
\hline \multicolumn{1}{c}{ Areas of Patient Safety } & Mean & Rank \\
\hline Team work within units & 4.06 & 1 \\
Organizational learning & 4.01 & 2 \\
Communication about error & 3.81 & 3 \\
Frequency of event reported & 3.73 & 4 \\
Communication openness & 3.45 & 5 \\
Team work across units & 3.44 & 6 \\
Handoff/ transition & 3.37 & 7 \\
Management support for patient & 3.19 & 8 \\
safety & & \\
Overall perception of patient safety & 3.13 & 9 \\
Non-punitive response & 3.08 & 10 \\
Supervisors expectation and action & 2.97 & 11 \\
promoting safety & & \\
Staffing & 2.90 & 12 \\
Total mean score & 3.43 & \\
\hline
\end{tabular}

Among 12 areas, the reported total mean score of patient safety was 3.43 with the highest score in teamwork within units followed by organizational learning. The lowest reported score was in staffing followed by supervisor's expectation and action promoting patient safety (Table 2.) 
Table 3: Difference of patient safety culture among selected demographic variables. $(n=93)$

\begin{tabular}{|c|c|c|c|c|c|c|c|c|c|c|}
\hline \multirow{4}{*}{$\begin{array}{c}\text { Variables } \\
\text { Age in years }\end{array}$} & \multicolumn{10}{|c|}{ Patient safety area } \\
\hline & \multicolumn{2}{|c|}{$\begin{array}{l}\text { Management } \\
\text { support }\end{array}$} & \multicolumn{2}{|c|}{$\begin{array}{c}\text { Frequency } \\
\text { of Events } \\
\text { Reported }\end{array}$} & \multicolumn{2}{|c|}{$\begin{array}{l}\text { Organizational } \\
\text { learning }\end{array}$} & \multicolumn{2}{|c|}{$\begin{array}{c}\text { Overall } \\
\text { perception }\end{array}$} & \multicolumn{2}{|c|}{$\begin{array}{l}\text { Handsoff/ } \\
\text { Transition }\end{array}$} \\
\hline & Mean & $* * \mathrm{P}$ & Mean & $* * \mathrm{P}$ & Mean & $* * \mathrm{P}$ & Mean & $* * \mathrm{P}$ & Mean & $* * \mathrm{P}$ \\
\hline & Rank & Value & Rank & Value & Rank & Value & Rank & Value & Rank & Value \\
\hline$\leq 25$ & 49.8 & $0.03 *$ & 37.7 & $0.006^{*}$ & 38.8 & 0.02 & 42.7 & 0.4 & 46.0 & 0.5 \\
\hline$>25$ & 38.3 & & 52.2 & & 50.9 & & 46.4 & & 42.7 & \\
\hline \multicolumn{11}{|l|}{ Working area } \\
\hline General ward & 46.7 & 0.2 & 43.5 & 0.7 & 50.5 & 0.9 & 58.5 & $0.001 *$ & 54.4 & $0.02 *$ \\
\hline Critical ward & 47.1 & & 49.3 & & 44.5 & & 39.0 & & 41.8 & \\
\hline
\end{tabular}

**Mann Whitney U test

*significant difference

There was significant difference between mean score of certain areas of patient safety with selected variables. Age of participant showed statistical difference with management support, organizational learning and frequency of event reported. Similarly working area showed significant difference with overall perception of patient safety and hands-off/transition. Result shows no significant differenceassociation with any other safety areas and variables like educational qualifications and work experiences (Table 3)

Table 4: Extent 4: Patient safety culture in the organization $(n=93)$

\begin{tabular}{lcc}
\hline \multicolumn{1}{c}{$\begin{array}{c}\text { *Mean score of } \\
\text { patient safety }\end{array}$} & Frequency & Percentage \\
\hline $\begin{array}{l}\text { Average patient safety } \\
(2.64-3.67)\end{array}$ & 78 & 83.9 \\
$\begin{array}{l}\text { Adequate patient safety } \\
(3.68-5.0)\end{array}$ & 15 & 16.1 \\
\hline
\end{tabular}

*Polit and Hungler as cited in Poudel K. the difference between highest possible mean score and lowest possible mean score divided by three gives an interval of 1.33. $(1-2.33=$ Poor, $2.34-3.67=$ average, $3.68-5=$ adequate)..$^{10}$

The analysis of patient safety culture within the organization was found to be average inside the organization, since $84 \%$ of the respondents reported it as average (Table 4).

\section{DISCUSSION}

In the current study, the mean score of patient safety ranged from 2.9 to 4.06 with overall mean score of
3.43. The highest rating was on teamwork within unit (4.06) and lowest on staffing (2.90) followed by supervisor's expectation and action promoting safety (2.97). The management support for patient safety was in number 8 with mean score of 3.19 among twelve areas of safety on ranking. This finding is consistent with the finding of the study conducted in Egypt, which revealed that overall dimension of safety culture mean score ranged from 1.76 to 4.55 with the mean of $3.33 \pm 0.58$. The highest rating was on team work climate whereas the rating was lowest on perception of management. ${ }^{12}$ Result of another study from Shahid Gangalal National Heart Centre (SGNHC) also showed teamwork within units, organizational learning and teamwork across units as strong areas and staffing, nun-punitive response and management support as weak areas of safety. The mean score of that study ranged from 2.90 to 4.16. ${ }^{10}$ A study from Iran comparing different aspects of patient safety culture showed that nurses provided the highest scores in organizational learning and general understanding of safety where as the lowest rating was with staff issues, extra-organizational 
teamwork and non-punitive response respectively. ${ }^{13}$ A study from Saudi Arabia showed that $73 \%$ of the nurses strongly agree that the teamwork in their unit is the strong area for supporting the patient's safety. However, $43.5 \%$ reported that their supervisors' and managers' expectations and actions promoting patient safety is the area to be improved. ${ }^{14}$ similar result is obtained from the study of Turkey i.e. the percentage of positive responses was highest for "teamwork within units" dimension and lowest for the "nonpunitive response to error" dimension. ${ }^{9}$

This study finding showed that mean score of overall perceptions of patient safety culture and hands off transitions had statistical difference with working area. Similarly age showed significant difference with mean of management support, organizational learning and frequency of event reported. Though professional qualification and work experience play significant role in safety issues there was no statistically significant difference of patient safety with these characterstics in this study. Study from hospital in Egypt documented statistical difference between mean scores of safety culture dimensions and work settings. Significant relationship was observed between socio-demographic characteristics and all dimensions of safety culture. ${ }^{12}$

In the present study $84 \%$ of respondent rated patient safety as average and only $16 \%$ rated it as adequate. This finding should grab immediate attention of management to make adequate patient safety within the organization. The result is in contrast with the result obtained from the study of SGNHC where 65\% of the respondents rated patient safety as adequate and $35 \%$ as average. Similarly finding of another study from Iran also contradicted finding of this study i.e. most of the nurses rated their department in terms of patient safety culture as excellent and very good..$^{13,15}$

Limitations of the study: This is a single setting study so study findings may not be generalizable.

\section{CONCLUSION}

The overall patient safety culture is average in the hospital. Among different domains of patient safety, teamwork within unit and organizational learning are stronger areas compared to staffing, supervisor's actions for safety promotion, teamwork across units and non-punitive response to error.

\section{REFERENCES}

1 WHO. Patient safety. World Health Organization, 2019. [Accessed 3 Jul2019]. Available from: https://www.who.int/ patientsafety/en/.

2 WHO. World Alliance For Patient Safety Forward Programme 2005. [Accessed 9 Jul2019]. Available from: www.who.int/ patientsafety.

3 Michael A. Durkin. Time to Move to a Cultural Era in Patient Safety of Values, Ethics and Leadership at Every Level,third Global Ministerial Summit on Patient Safety. 2018 . [Accessed 9 Jul2019]. Available from: https:// www.mhlw.go.jp/psgms2018/pdf/document/1_ Document.pdf

4 Guldenmund FW. The nature of safety culture: a review of theory and research. Saf.sci. 2000; 34 (1-3): 215-257.[Accessed 22 July 2019]. Available from. https://doi.org/10.1016/S09257535(00)00014-X

5 WHO | 10 facts on patient safety. WHO 2018. [Accessed 3 Jul2019]. Available from: http:// www.who.int/features/factfiles/patient_safety/ patient_safety_facts/en/index $8 . h t m l$

6 Institute of Medicine.2000. To Err Is Human:Building a Safer Health System. Washington DC: The National Academic Press. [Accessed 30 July 2019]. Available from. https://doi.org/10.17226/9728.

7 Wilson RM, Runciman WB, Gibberd RW, Harrison BT, Newby L, Hamilton JD. The Quality in Australian Health Care Study. Med J Aust. 1995; 163(9): 458-71.

8 WHO. Crossing the Global Quality Chasm: Improving Health Care Worldwide : Health and Medicine Division. 2018. [Accessed 3 Jul 2019]. Available from; http://nationalacademies.org/ hmd/Reports/2018/crossing-global-qualitychasm-improving-health-care-worldwide.aspx. 
9 Yilmaz Z, Goris S. Determination of the patient safety culture among nurses working at intensive care units. Pakistan J Med Sci. 2015;31(3):597-601[Accessed on 31 July 2019]. Available from: doi:10.12669/ pjms.313.7059.

10 paudel krishna. Assessment of Patient Safety Culture among Nurses in Shahid Gangalal National Heart Centre. J Nepal Nurs Counc. 2016; 10: 1-6.

11 Agency for Healthcare Research and Quality (AHRQ).Rockville,MD. Hospital survey on patient safety culture.Available from:https:// www.ahrq.gov/sops/surveys/hospital/index. html.

12 Abdou HA, Saber KM. A Baseline Assessment of Patient Safety Culture among Nurses at Student University Hospital. World J Med Sci. 2011; 6(1): 17-26.
13 Borji M, Molavi S, Salimi E, Bastami Y. Studying Patient Safety Culture from the Viewpoint of Nurse in educational hospitals Ilam City. Int J Med Res Heal Sci. 2016; 5(12): 198-202.

14 Alonazi NA, Alonazi AA, Saeed E, Mohamed S. The perception of safety culture among nurses in a tertiary hospital in Central Saudi Arabia. Sudan J Paediatr. 2016;16(2):51-58. [Accesses on 22 July 2019]. Available from. https://europepmc.org/articles/PMID28096559 /PMC5237835

15. Rijal E, Silwal S, Thapa S, Basnet S, Bhagat S. Nurses Knowledge on Management of Patient Receiving Spinal Anaesthesia in a Government Hospital. JKAHS [Internet]. 13Aug.2019 [cited 11Dec.2019];2(2). Available from: https:// jkahs.org.np/jkahs/index.php/jkahs/article/ view/92 